by the British government. Another question to receive close scrutiny will be the extent to which modified genes can be transferred to other plants, and what effect this might have on, for example, organic produce. A third question is whether herbicide tolerance can spread to nearby plants, whether weeds or other crops.

The limited evidence available so far has left researchers apparently divided on the risks to non-target insects from $B t$ crops. William Hutchison and colleagues from the department of entomology at the University of Minnesota, for example, told a meeting of the Entomological Society of America last month that they found no difference in the numbers of 'beneficial' insects when they sampled fields of $B t$ sweetcorn and non- $B t$ corn in Minnesota (see http://www.ent.iastate.edu/entsoc/ncb99/prog/abs/d51.html).

In contrast, Nicholas Birch, a research entomologist at the Scottish Crop Research Institute in Dundee, has demonstrated in lab studies that an anti-aphid toxin expressed by an experimental GM potato reduces the fertility and shortens the lives of ladybirds that eat the target aphids. Critics, though, point out that the toxin in question, snowdrop lectin, is unlikely to be approved for a GM crop given previous evidence of its toxicity.

Perhaps a more realistic pointer to potential dangers has come from Angelika Hilbeck, of the Swiss Federal Research Station for Agroecology and Agriculture in Zurich, who has found that lacewings, another beneficial insect, have higher death rates when fed the larvae of target insects that have eaten $B t$ corn compared with larvae fed on ordinary corn.

But Hilbeck's studies were conducted in the laboratory (see Environmental Entomology 27, 480-487; 1998). Under farm conditions, the results may be different, as the target insect - the European cornborer - lives inside corn stalks, where under normal conditions it is largely protected from lacewings.

Research has also been under way for some time to assess the impact on nearby flora of herbicide-tolerant GM crops. Researchers from Denmark, France and the United States have already suggested that the results of trial experiments indicate that herbicide-tolerant genes can in principle 'escape' from GM plants to nearby weedy relatives through pollen transfer.

Similarly Anne-Marie Chevre, a plant researcher at the Institut National de la Recherche Agronomique in Le Rheu, France, has found that oilseed rape genetically modified to withstand herbicide easily produced fertile offspring when crossed with a common weed, the wild radish - although she also found that the herbicide-tolerance genes became more diluted with each generation of hybrids.

Scientists working for environmentalist groups are among those who claim that such

\title{
Japan defends its drive for self-sufficiency
}

Despite widespread public concern over genetically modified food, Japan's scientists - in concert with those in other countries - have only recently begun to address questions on the potential long-term risks to human health and the environment from GM crops.

On 1 April, the Ministry of Agriculture, Forestry and Fisheries (MAFF) embarked on the government's first project to examine the risks from GM crops. As elsewhere, the project will focus on the long-term impacts of herbicide- and insect-tolerant crops on ecology and on agricultural practices.

A substantial proportion of the Japanese public, like their counterparts in Europe, are uneasy about GM foods. Some invoke ethical concerns about the manipulation of genes. Another reason is a relative lack of public understanding of genetic modification techniques. A third reason is government reluctance to label GM foods.

But other factors may be at work. According to Naoto Shibuya, a researcher in bioengineering at the National Institute of Agro-Environmental Sciences in Tsukuba, public unease can partly be attributed to an absence of effective public communication of the risks. Shibuya says scientists need to communicate in a way that "indicates what is understood and what is not".

A low level of public confidence in GM foods is not good news for the government, which is relying on GM agriculture to make Japan self-sufficient in food. Unsurprisingly, finding ways of allaying public concerns is a key aim of the MAFF research project.

Japan's GM regulations are modelled on a framework set out by the Organization for Economic Cooperation and Development (OECD), with a strong emphasis on the concept of 'substantial equivalence' (see page 652). But critics question 'substantial equivalence' as a basis for deciding whether a product is safe, and argue that there is no

gene transfer could encourage the proliferation of 'superweeds', which might turn out to be highly invasive.

The consensus from a recent gathering of scientists, regulators and research managers in Bethesda, Maryland, convened to consider the ecological impacts of GM crops, was that there is little risk of enhanced weediness from the handful of transgenic plants on the market. Their genetically enhanced traits would not confer any competitive advantage over other plants, and would eventually die out, it was concluded.

But overall the jury is still out. For example, the scientists attending the Bethesda meeting agreed that, when many different GM plants exchange genes, a kind of 'gene stacking' of multiple desirable traits could

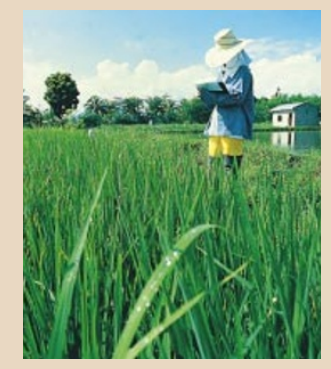

substitute for long-term risk assessments. "The regulators have overlooked the potential residual toxicity after several growing seasons, and the consequences on Farm tests: Japan has tough rules on field trials. genetic diversity," says Setsuko Yasuda, directorgeneral of Japan's Consumers' Association.

But representatives of the Ministry of Health and Welfare, as well as MAFF, which are both involved in the approval of GM products, claim that the chances of GM crops posing health and environmental risks are negligible, and that such risks would be detected during safety tests.

In some ways, Japan's regulatory system for GM crops is tougher than in other industrialized countries. Once a potentially useful crop plant has been developed, small scale, isolated field trials are carried out, followed by cultivation over at least one generation in a farm-scale environment. Farm-scale trials are not a regulatory requirement in many $\mathrm{OECD}$ countries.

Although the government is keen to press ahead with the development of GM crops, the private sector is more cautious than in other industrialized countries. Companies such as Japan Tobacco, Kirin Beer and Suntory are carrying out farm-scale trials including virus-resistant rice and petunia but there are no immediate plans to commercialize any of these products.

According to government sources, this is because few locally-based companies are keen to be the first to commercialize GM crops because of a fear that this could create a negative image of the company, and perhaps trigger a boycott of its products.

theoretically produce a highly competitive weed. And some, such as Allison Snow, an ecologist at Ohio State University, point out that this is not likely to be known until many GM crops are in wide use.

Nor do researchers yet know whether a fitness-improving gene - such as one that confers resistance to pests, herbicides or drought - will necessarily make a weed or a GM crop more invasive. In the case of herbicide resistance, unless the weed is sprayed with herbicide, there should be no selection pressure favouring the survival of resistant plants, and the trait should die out in time.

Representatives of the biotechnology industry are among those who believe strongly that the benefits to agriculture and the environment from GM crops tend to be 